\title{
Age estimation by teeth periodontosis and transparency: accuracy of Lamendin's method on a Brazilian sample
}

\author{
Juliana Ribeiro Lopes' ${ }^{1}$, Simone Borges Braga dos Santos Queiroz', Mário Marques Fernandes ${ }^{1,3}$, \\ Luiz Airton Saavedra de Paiva ${ }^{2}$, Rogério Nogueira de Oliveira ${ }^{1}$
}

\author{
${ }^{1}$ Universidade de São Paulo - USP, School of Dentistry, Department of Community Dentistry, Area of Forensic Dentistry, São Paulo, SP, Brasil \\ ${ }^{2}$ Instituto de Medicina Legal de Guarulhos - IML, Center for Forensic Sciences Studies and Research, Guarulhos, SP, Brasil
}

${ }^{3}$ Ministério Público do Rio Grande do Sul, Biomedical Service, Porto Alegre, RS, Brasil

Received for publication: January 28, 2014 Accepted: March 10, 2014

Correspondence to: Mário Marques Fernandes Av. Prof. Lineu Prestes, 2227

Cidade Universitária CEP 05508-900 São Paulo-SP, Brasil Phone: +55 1130917891 Fax: +55 1130917874 E-mail:mario-mf@live.com

\begin{abstract}
Aim: To apply the Lamendin et al. (1992) technique on a Brazilian sample to assess its accuracy on this specific population. Methods: The authors present two measurements in single-rooted teeth: the peridontosis and transparency of the root. Then, these variables are inserted in an equation to estimate the individual's age. The sample comprised 49 teeth obtained from the collection of the Forensic Medicine Institute of Guarulhos, Brazil. Statistical analysis was performed with $t$ and paired $t$ tests, comparing chronological and estimated ages. Results: It was possible adjust the original formula for Brazilians by linear regression analysis: $A=(P \times 0.18)+(T \times 0.47)$ +31.77 . Where, $A=$ age; $P=$ (periodontosis height $x$ 100)/root height; and $T=($ transparency height $x$ 100)/root height. Conclusions: The method is accurate only for young adults but it could be used with caution in individuals between 45 and 60 years of age to assist in estimating an age range. However, the technique loses its efficacy in older individuals.
\end{abstract}

Keywords: forensic anthropology; age determination by teeth; forensic dentistry.

\section{Introduction}

Age determination by teeth is an important part of Forensic Dentistry and Anthropology, since it valuably assists in cases of identification. For many years and still now, the scientific community have produced a large number of researches on this topic. Several of them are based on developmental stages of teeth, which makes them suitable for estimating age of children and adolescents ${ }^{1-4}$. For adults, the methods are often based on degenerative modifications, such as attrition, periodontosis, transparency of the root, secondary dentin, cementum apposition and root resorption.

Since Gustafson ${ }^{5}$ (1950) first published his work on age determination by degenerative changes in teeth, several authors ${ }^{6-8}$ developed other methods based on the characteristics he described, including Lamendin et al. ${ }^{9}$ (1992). The technique was developed to be plain and with the purpose to estimate adults' age at death. It consists in the analysis of two dental variables (periodontosis and transparency) and three height measurements (periodontosis, transparency and root),applying the numbers to the following formula: $\mathrm{A}$ (age $)=(\mathrm{P} \times 0.18)+(\mathrm{T}$ $\mathrm{x} 0.42)+25.53$. Where, $\mathrm{A}=$ age; $\mathrm{P}=$ (periodontosis height $\mathrm{x} 100$ )/root height; 
and $\mathrm{T}=$ (transparency height $\mathrm{x} 100$ )/root height. The method is a good option to be used in forensic cases.

Therefore, the aim of this study was to apply Lamendin's technique to a Brazilian sample in order to assess its efficacy on this population.

\section{Material and methods}

The technique, as described by Lamendin et al. ${ }^{9}$ (1992), was applied to 49 single-rooted teeth from 26 skeletonized individuals. The sample consisted of a collection of corpses formerly buried in a cemetery in Guarulhos, SP, Brazil, and then donated by their families to the Forensic Sciences Study and Research Center at the Forensic Medicine Institute of Guarulhos. Donations were made 3 years after death and burial. Age and gender were known with certainty.

The region of Guarulhos has a humid subtropical climate with annual averages of $19^{\circ} \mathrm{C}$ temperature, 81.1 air relative humidity and $1470 \mathrm{~mm}$ rainfall. The rain concentrates in the summer months, contrasting with the dry period, which corresponds to the winter months (July and August). The soil from where the skeletons were taken has a $\mathrm{pH}$ around 5.5 , which means that the concentration of hydrogen ions is high, making it an acid soil.

The original method advocates the measurements to be made on the labial surface of the root, which was honored in this study. However, in some cases this surface was exposed due to lack of bone structure in this area and was damaged during cleaning of the skulls, impairing visualization on this surface. In such cases, measurements were made on the most labial part of the mesial surface.

As defined by the authors, the periodontosis is a yellowish area darker than the enamel, but lighter than the rest of the root. It corresponds to the maximum distance between the cement enamel junction and insertion line of soft tissues, as shown in Figure 1.

The root transparency results from hydroxyapatite

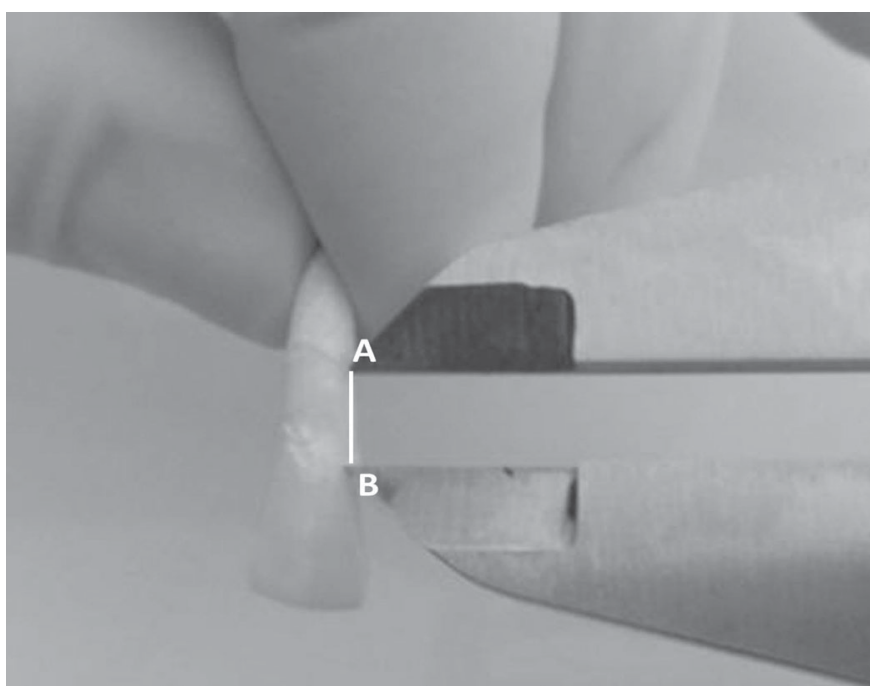

Fig. 1: Periodontosis measure: the maximum distance between the soft tissue insertion line (point A) and the cement enamel junction (point B). Always made on the labial surface of root, and facing the observer.

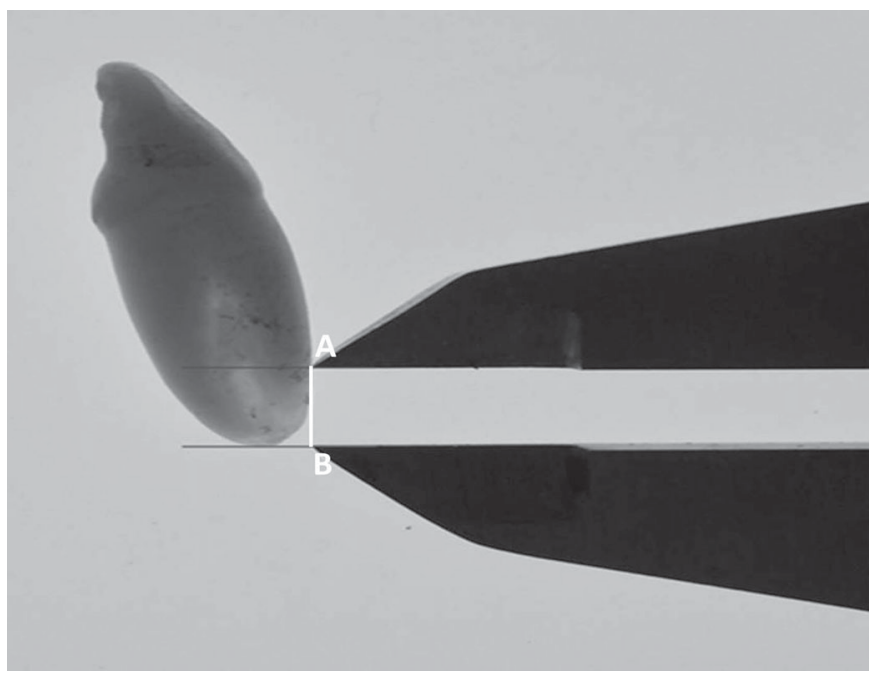

Fig. 2: Root transparency measurement: the maximum length of transparency from the apex on labial surface. The tooth is positioned with the proximal face in contact with light box to aid visualizing root transparency on the labial surface. Two parallel lines are drawn, one on the upper region (point A) and other on the lower region (point B) of labial transparency area.

crystals deposition inside the dentinal tubules, and the maximum length of transparency is measured from the apex. To avoid erroneous measurements, in the present study all measurements were taken at a starting point on an imaginary line at the height of the root apex, as illustrated in Figure 2.

A digital sliding caliper was used to make all measurements and a light box was used to aid visualization of root transparency. The observer was unaware of the chronological age during this process.

To evaluate intra- and inter-observer variation, BlandAltman analysis with Pitman's test of difference in variance was used. To verify efficacy of the method, the estimated ages obtained by applying measurements to Lamendin's formula were compared to chronological ages and statistically analyzed with $\mathrm{t}$ and paired $\mathrm{t}$ tests. All analyses were performed with STATA ${ }^{\circledR} 12$ (Stata Corp., College Station, TX, USA), and a $5 \%$ level of significance was set.

The study was approved by the Ethics Research Committee of University of São Paulo School of Dentistry under protocol number 76/11 and CAAE 0086.0.017.000-11.

\section{Results}

At the time the investigation was conducted, there were 66 individuals in the collection; 27 of them had viable teeth for the research. However, after the measurements, it was revealed that one skull belonged to a 17 year-old boy, which led to its exclusion from the sample, due to the Lamendin's formula constant (25.53), which does not allow for estimating the age of individuals less than 25 years old. Therefore, the final sample comprised 49 teeth from 26 skulls. Whenever possible, two teeth were extracted from the same individual, thus 14 teeth from 7 females and 35 teeth from 19 males were obtained.

Two weeks after measurements, 10 teeth were randomly selected to test intra- and inter-observer variation. The second 
observer was calibrated and also blinded. Variations were never higher than $1 \mathrm{~mm}$ and Bland-Altman analysis with Pitman's test of difference in variance showed that the measurements were statistically equal between observers and the main observer $(\mathrm{p}>0.05)$.

Ages at death varied from 30 to 81 years, with a mean of 49.08 years. The sample was divided into age groups, as displayed in Table 1. This table also shows the comparative analysis between estimated and chronological ages for each group performed with paired t test. The sample was also divided according to gender (Table 2). Table 3 shows compares the differences in age estimation using Lamendin's formula with and without adjustment to Brazilian population.

\section{Discussion}

Although Lamendin et al. ${ }^{9}$ (1992) states that the method is not suitable to estimate the age of young adults, the formula produced better results in that group of the Brazilian sample with a mean error (ME) of 1.22 in the $\leq 39$-year-old group. It is worth noting that, as individuals between 40 and 45 years were included in the group, accuracy and variation improved, suggesting that this technique is very efficient in this age group. Several authors had similar results ${ }^{10-14}$, but others also presented better outcomes in groups over 50 years of age ${ }^{15-16}$.

The other age groups did not present statistically significant results, but the 40-59-year-old group had a much lower ME than group $\geq 60$. This shows that the method is not suitable for individuals over 60 years and it may be used to estimate only the age range for subjects between 40 and 60 years. Most studies show similar results, in which ME for adults over 60 years of age presents a high variation
$(\mathrm{ME}>15)^{10-14,16}$. It is also agreed among the researchers that in older groups, age is underestimated while in younger adults, age is overestimated $\mathrm{d}^{10-13,15-16}$.

In the total sample, age was best estimated in males, which could be explained by the difference in sample size. Although no significant differences were observed between genders, it may be noticed that in the 40-59-year-oldgroup females showed a much lower ME than males. A study on a larger sample is required to clarify if this difference has statistical significance. The literature shows diverging results as to the correlation of the technique with gender; some authors found best results for males ${ }^{10,14}$, as opposed to others that observed better estimates forfemales ${ }^{16}$, while other study reported no difference regarding gender ${ }^{15}$.

In general, authors ${ }^{9,11,13-14,16}$ do not specify several sample conditions, such as inhumation, exposure to substances or state of teeth. In the present study such aspects are reported because they may influence or even determine the conservation of anatomical structures (teeth), which directly affects the method application.

It was also observed that some studies do not make clear whether they were blinded or not, but performed intraand inter-examiner ${ }^{10,16}$ correlations, one of theminaccurate ${ }^{11}$. In the present study both criteria were respected to assure greater reliability and reproducibility of results.

Ubelaker and Prince ${ }^{15}$ (2002) observed differences between blacks and whites, but did not go deep into the subject, not specifying whether a group would be more accurate than the other, unlike Martrille et al. ${ }^{16}$ (2007) who observed better results in whites. Foti et al. ${ }^{10}$ (2001) found higher accuracy in the mandible than in the maxilla. In the present study these classifications were not considered, mainly to have a closer approach to the forensic reality, where the

Table 1- Estimated age compared with chronological age

\begin{tabular}{llccccc}
\hline $\begin{array}{l}\text { Year } \\
\text { range }\end{array}$ & $\mathbf{n}$ & $\begin{array}{c}\text { Mean } \\
\text { estimated age }\end{array}$ & $\begin{array}{c}\text { Mean } \\
\text { chronological age }\end{array}$ & $\begin{array}{c}\text { Mean error } \\
\text { (ME) }\end{array}$ & $\begin{array}{c}\text { Standard } \\
\text { deviation (SD) }\end{array}$ & $\boldsymbol{p}$-value \\
$\leq 39$ & 16 & 36.00 & 34.37 & 1.62 & 1.22 & 0.204 \\
$40-59$ & 18 & 38.88 & 46.44 & -7.55 & 2.52 & 0.008 \\
$\geq 60$ & 15 & 46.86 & 67.93 & -21.06 & 2.43 & 0.000 \\
\hline$\leq 45$ & 26 & 38.00 & 37.38 & 0.61 & 0.97 & 0.532 \\
$>45$ & 23 & 43.08 & 62.30 & -19.21 & 2.06 & 0.000 \\
\hline
\end{tabular}

Table 2- Estimated age compared with chronological age according to gender.

\begin{tabular}{lcccccc}
\hline Gender and age & $\mathbf{n}$ & Mean estimated age & Mean chronological age & ME & SD & $p$ \\
Male (total) & 35 & 39.91 & 47.57 & -7.65 & 11.77 & 0.000 \\
Female (total) & 14 & 41.57 & 52.85 & -11.28 & 14.48 & 0.012 \\
\hline$\leq 39$ & & & & & & \\
Male & 12 & 35.33 & 34.00 & 1.33 & 5.46 & 0.416 \\
Female & 4 & 38.00 & 35.50 & 2.50 & 3.00 & 0.194 \\
\hline $40-59$ & & & & & & \\
Male & 14 & 38.78 & 47.28 & -8.50 & 12.00 & 0.020 \\
Female & 4 & 39.25 & 43.50 & -4.25 & 2.50 & 0.042 \\
\hline$\geq 60$ & & & & & & \\
Male & 9 & 47.77 & 66.11 & -18.33 & 7.95 & 0.000 \\
Female & 6 & 45.50 & 70.66 & -25.16 & 10.66 & 0.002 \\
\hline
\end{tabular}


Table 3 - Sample data, chronological age and estimates by the Lamendin original method and adjusted to the Brazilian population

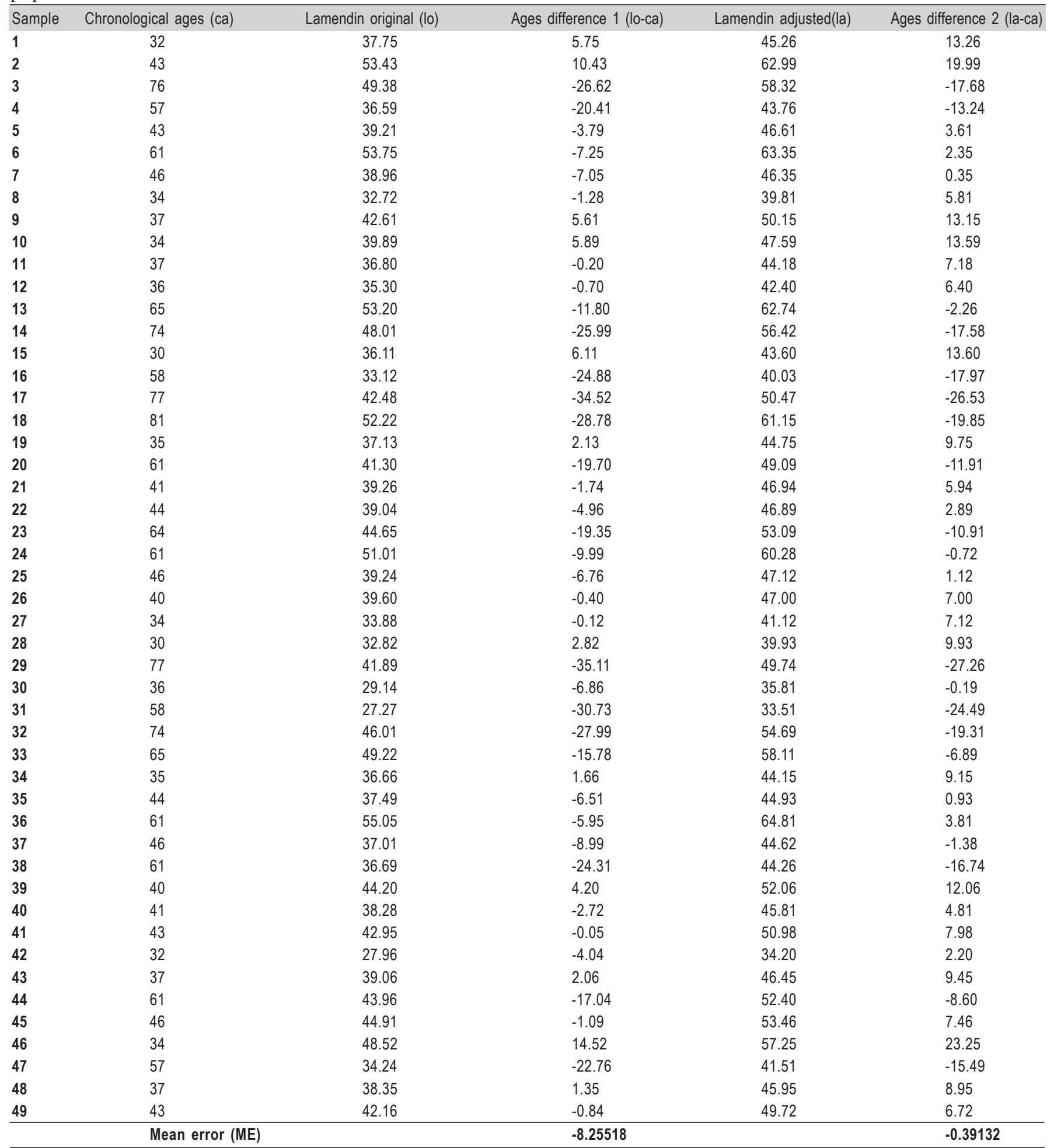

expert does not know initially the age of a skull or a single tooth.

Most of the collected teeth were canines $(n=20)$ and lateral incisors $(\mathrm{n}=17)$; there were only 3 premolars and 6 central incisors. Therefore, the number of different types of teeth was insufficient to perform a statistical analysis.

It has been suggested that there are significant differences between populations ${ }^{11-15,17}$. For this reason, a specific formula for Brazilians was developed by linear regression analysis.

The new formula is as follows:

$\mathrm{A}=(\mathrm{P} \times 0.18)+(\mathrm{T} \times 0.47)+31.77$

Where, $\mathrm{A}=$ age; $\mathrm{P}=$ (periodontosis height $\times 100) /$ root height; and $\mathrm{T}=$ (transparency height $\mathrm{x} 100$ )/root height. 
In order to test its accuracy in a Brazilian population, a different sample would be required, which was not available for this research. In addition, the sample used to develop this formula was relatively small, and the youngest individuals were 30 years old, which made the constant to be relatively high and impaired age estimation of adults younger than 31 years of age.

Lamendin's method is a suitable option for estimating ages of Brazilians between 30 and 45 years old. The technique loses its efficacy in other age groups, but with proper care, it could be used to help establishing age ranges for individuals between 45 and 60 years. Further research is required to test the suggested formula or even develop a new one with better results in the Brazilian population.

\section{References}

1. Moorrees $\mathrm{CF}$, Fanning $\mathrm{EA}$, Hunt EE Jr. Age variation of formation stages for ten permanent teeth. J Dent Res. 1963; 42: 1490-502.

2. Demirjian A, Goldstein H, Tanner JM. A new system of dental age assessment. Hum Biol. 1973; 45: 211-27.

3. Fernandes MM, Tinoco RLR, Braganca DPP, Lima SHR, Francesquini Junior L, Daruge Junior E. Age estimation by measurements of developing teeth: accuracy of Cameriere's method on a Brazilian sample. J Forensic Sci. 2011; 56: 1616-9.

4. Cameriere R, Ferrante L, Cingolani M. Age estimation in children by measurement of open apices in teeth. Int J Legal Med. 2006; 120: 49-53.

5. Gustafson G. Age determination on teeth. JAm DentAssoc. 1950; 41:45-54.

6. Bang G, Ramm E. Determination of age in humans from root dentin transparency. Acta Odontol Scand. 1970; 28: 3-35.

7. Kvaal SI, Kolltveit KM, Thomsen IO, Solheim T. Age estimation of adults from dental radiographs. Forensic Sci Int. 1995; 74: 175-85.

8. Cameriere R, Ferrante L, Cingolani M. Variations in pulp/tooth area ratio as an indicator of age: a preliminary study. J Forensic Sci. 2004; 49: 317-9.

9. Lamendin H, Baccino E, Humbert JF, Tavernier JC, Nossintchouk RM, Zerilli A. A simple technique for age estimation in adult corpses: The two criteria dental method. J Forensic Sci. 1992; 37: 1373-9.

10. Foti B, Adalian P, Signoli M, Ardagna Y, Dutour O, Leonetti G. Limits of the Lamendin method in age determination. Forensic Sci Int. 2001; 122: 101-6.

11. Sarajliæ N, Cihlarz Z, Klonowski EE, Selak I, Brkiæ H, Topiæ B. Twocriteria dental aging method applied to a Bosnian population: comparison of formulae for each tooth group versus one formula for all teeth. Bosn J Basic Med Sci. 2006; 6: 78-83.

12. Meinl A, Huber CD, Tangl S, Gruber GM, Teschler-Nicola M, Watzek G. Comparison of the validity of three dental methods for the estimation of age at death. Forensic Sci Int. 2008; 178: 96-105.

13. Prince DA, Konigsberg LW. New formulae for estimating age-at-death in the Balkans utilizing Lamendin's dental technique and Bayesian analysis. J Forensic Sci. 2008; 53: 578-87.

14. Ubelaker DH, Parra RC. Application of three dental methods of adult age estimation from intact single rooted teeth to a Peruvian sample. J Forensic Sci. 2008; 53: 608-11.

15. Prince DA, Ubelaker DH. Application of Lamendin's adult dental aging technique to a diverse skeletal sample. J Forensic Sci. 2002; 47: 107-16.

16. Martrille L, Ubelaker DH, Cattaneo C, Seguret F, Tremblay M, Baccino E. Comparison of four skeletal methods for the estimation of age at death on white and black adults. J Forensic Sci. 2007; 52: 302-7.

17. González-Colmenares G, Botella-López MC, Moreno-Rueda G, Fernández-Cardenete JR. Age estimation by a dental method: A comparison of Lamendin's and Prince \& Ubelaker's technique. J Forensic Sci. 2007; 52: $1156-60$. 